\title{
Endothelium-derived free radicals: for worse and for better
}

\author{
Paul M. Vanhoutte
}

Institut de Recherches Internationales Servier, 6 Place des Pléiades, 92415 Courbevoie Cedex, France. Phone: 33-1-55-72-61-23; Fax: 33-1-55-72-72-76; E-mail: vanhoutt@servier.fr.

In a recent issue of the $J C I$, Matoba et al. (1) argue that hydrogen peroxide $\left(\mathrm{H}_{2} \mathrm{O}_{2}\right)$ derived from endothelial nitric oxide synthase (eNOS) acts as an endothelium-derived hyperpolarizing factor (EDHF) in small mesenteric arteries of the mouse. Their data are convincing, and if their conclusion is correct, $\mathrm{H}_{2} \mathrm{O}_{2}$ now joins nitric oxide $(\mathrm{NO})(2,3)$, superoxide anions (4), and potassium ions (5) on the list of small inorganic molecules that carry regulatory messages from the endothelium to vascular smooth muscle cells and so contribute to intercellular signaling in the vascular wall. The effect of $\mathrm{H}_{2} \mathrm{O}_{2}$ adds another layer to our already complex description of endothelium-dependent hyperpolarization (Figure 1 ; see refs. 6-8).

\section{$\mathrm{H}_{2} \mathrm{O}_{2}$ and vascular relaxation}

Matoba et al. (1) conclude that eNOS generates superoxide anions, which are converted by superoxide dismutase (SOD) to $\mathrm{H}_{2} \mathrm{O}_{2}$. This mediator then acts on ion channels on the vascular smooth muscle, increasing $\mathrm{K}^{+}$conductance and causing hyperpolarization and relaxation of the vascular smooth muscle (9-11). Early evidence that $\mathrm{H}_{2} \mathrm{O}_{2}$ can participate in endotheliumdependent relaxation came from work with canine coronary arteries, where the generation of superoxide anions leads to catalase-sensitive vascular relaxation. Because this response, as observed using arterial rings maintained ex vivo, is more evident in rings with than in those without endothelial cells (12), these experiments suggested that $\mathrm{H}_{2} \mathrm{O}_{2}$ facilitates endotheliumdependent relaxation. The present findings imply that this facilitation was due to transformation in the endothelial cells of superoxide anions into $\mathrm{H}_{2} \mathrm{O}_{2}$. Hence, the study by Matoba et al. (1) now helps to establish $\mathrm{H}_{2} \mathrm{O}_{2}$ 's causal role in this response. One excit-

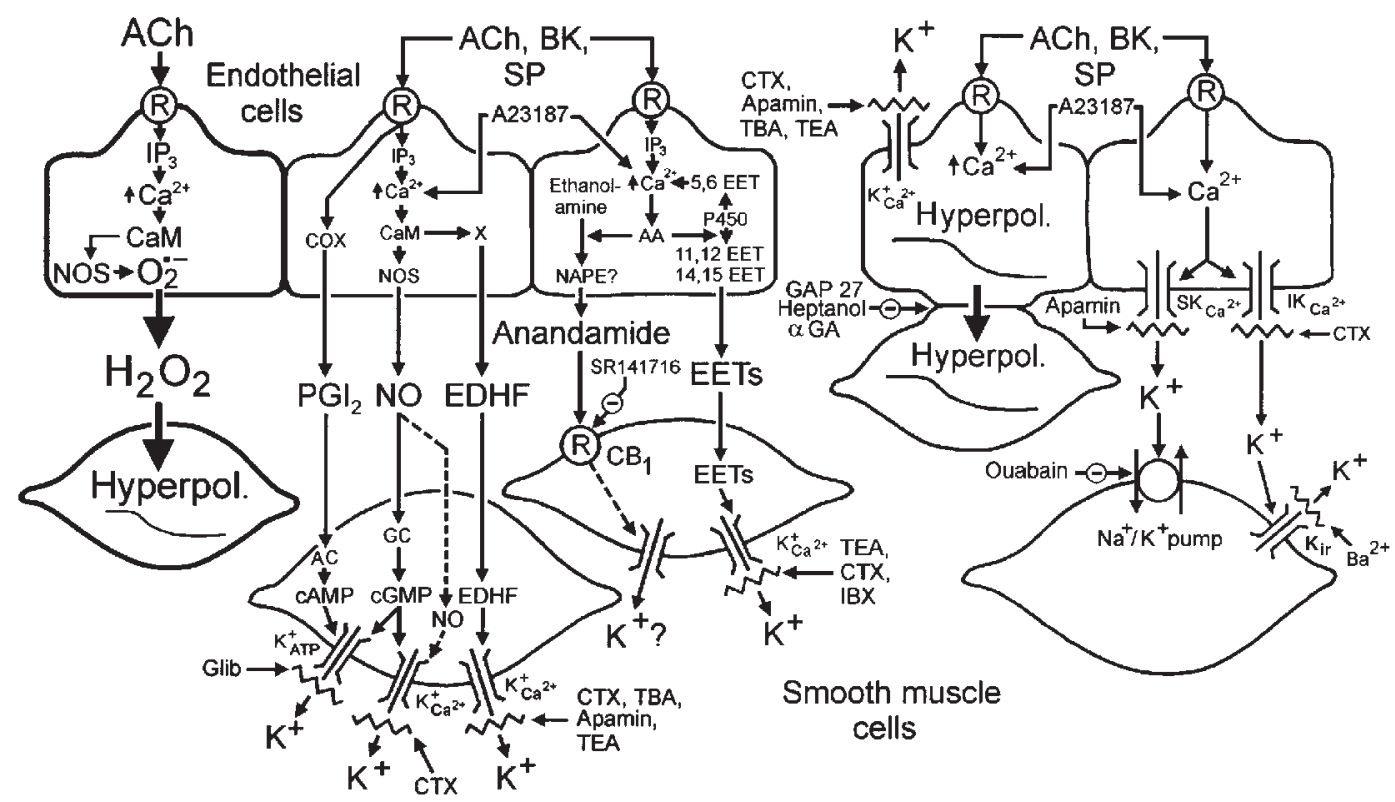

Figure 1

Multiplicity of mechanisms leading to endothelium-dependent hyperpolarization. The mechanism proposed by Matoba et al. (1) is highlighted. Substances such as acetylcholine (ACh), bradykinin (BK), and substance $\mathrm{P}(\mathrm{SP})$, through the activation of $\mathrm{M}_{3}$-muscarinic, $\mathrm{B}_{2}$-bradykinin, and NK${ }_{1}$-neurokinin receptor subtypes, respectively, and agents that increase intracellular calcium, such as the calcium ionophore A23187, release endotheliumderived hyperpolarizing factors. CaM, calmodulin; COX, cyclooxygenase; EET, epoxyeicosatrienoic acid; IP 3 , inositol trisphosphate; GC, guanylate cyclase; NAPE, $\mathrm{N}$-acylphosphatidylethanolamine; Hyperpol., hyperpolarization; $\mathrm{NOS}, \mathrm{NO}$ synthase; $\mathrm{O}_{2}{ }^{\bullet-}$, superoxide anions; $\mathrm{PGl}_{2}$, prostacyclin; $\mathrm{P} 450$, cytochrome P450 monooxygenase; $R$, receptor; $X$, putative EDHF synthase. SR141716 is an antagonist of the cannabinoid $C_{1} B_{1}$ receptor subtype $\left(C_{1}\right)$. Glibenclamide (Glib) is a selective inhibitor of ATP-sensitive potassium channels $\left(\mathrm{K}^{+}{ }_{\text {ATP }}\right)$. Tetraethylammonium (TEA) and tetrabutylammonium (TBA) are nonspecific inhibitors of potassium channels when used at high concentrations (> $5 \mathrm{mM}$ ), while at lower concentrations (1-3 mM) these drugs are selective for calcium-activated potassium channels $\left(\mathrm{K}^{+} \mathrm{Ca2}^{+}\right)$. Iberiotoxin (IBX) is a specific inhibitor of large conductance $\mathrm{K}^{+} \mathrm{Ca}^{+}$. Charybdotoxin (CTX) is an inhibitor of large conductance $\mathrm{K}^{+} \mathrm{Ca}_{2}+$, intermediate conductance $\mathrm{K}^{+} \mathrm{Ca}_{2+}\left(\mathrm{IK}_{\mathrm{Ca} 2}{ }^{+}\right)$, and voltage-dependent potassium channels. Apamin is a specific inhibitor of small conductance $\mathrm{K}^{+} \mathrm{Ca}_{2}{ }^{+}\left(\mathrm{SK}_{\mathrm{Ca}_{2}}\right)$. Barium $\left(\mathrm{Ba}^{2+}\right)$, in the micromolar range, is a specific inhibitor of the inward rectifier potassium channel ( $K_{\text {ir }}$ ). GAP 27 (an eleven-amino acid peptide possessing conserved sequence homology to a portion of the second extracellular loop of

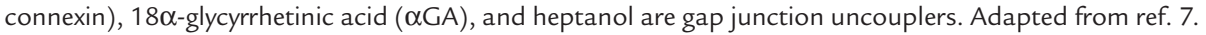


ing conclusion of this study is that $\mathrm{H}_{2} \mathrm{O}_{2}$ is generated by the action of the eNOS. The proposal that eNOS can generate oxygen-derived free radicals is not unprecedented (13-15), but the notion that this happens physiologically, in normal mouse arteries exposed to acetylcholine, is novel. These conditions differ dramatically from those in which NO synthase has been observed to produce oxygen-derived free radicals, namely the absence of normal substrates or cofactors $(13,14)$.

$\mathrm{H}_{2} \mathrm{O}_{2}$ clearly differs from all other putative mediators of endotheliumdependent hyperpolarization. At least in the small mesenteric arteries studied by Matoba et al. (1), myoendothelial gap junctions are not required as a conduit for $\mathrm{H}_{2} \mathrm{O}_{2}$ 's EDHF activity. Moreover, its activity can be abolished by using a suitable combination of $\mathrm{K}^{+}$ channel blockers, a hallmark of EDHFmediated responses (5-8). By these criteria, $\mathrm{H}_{2} \mathrm{O}_{2}$ appears to be an EDHF in its own right.

The field of EDHF research is mired with species differences and with functional differences between small and large blood vessels (see refs. 5-8). For this reason, it is not clear whether the present findings, made in small arteries of the mouse, can be extended to the small and large blood vessels of other species. For example, in coronary arteries of the dog, catalase, which abolishes EDHF-mediated response in the experiments of Matoba et al. (1), has minimal, if any, effects on the response to acetylcholine (12). This is a most important issue, as it may well be that in the vascular periphery the effect of EDHFs on vascular tone overwhelms that of endothelium-derived NO, thus controlling peripheral resistance and arterial blood pressure. If so, the cardiovascular scientific community, which took fifteen years to accept that NO participates in endotheliumdependent regulation of vascular tone, may have to adjust itself to the idea that this gaseous mediator is not the only such endothelium-derived regulator.

\section{Reactive oxygen species reconsidered}

This report also reopens the broader question of the regulatory role of oxygen-derived free radicals in general, particularly in endothelium-dependent responses. So far, the perception has been that those radicals, in particular superoxide anions, contribute mainly to destructive processes. This is attributed to the scavenging effect of superoxide anions on endothelium-derived NO (16), which leads to the production of the ill-reputed peroxynitrite. In addition, both superoxide anions and $\mathrm{H}_{2} \mathrm{O}_{2}$ can be transformed into hydroxyl radicals, which can catalyze the production of vasoconstrictor prostanoids. These mediators act directly on vascular smooth muscle cells to induce contraction (17). While this activity is thought of as pathological, superoxide anions in large cerebral arteries and certain other blood vessels may play a valuable role in the response to stretch to allow for vascular autoregulation $(4,18)$.

The identification of $\mathrm{H}_{2} \mathrm{O}_{2}$ as an EDHF provides a satisfying explana- tion of the negative feedback (see, for example, ref. 19) exerted by NO on endothelium-dependent relaxation, at least in small mesenteric arteries of the mouse (1). Since NO and superoxide anions (the precursor of $\mathrm{H}_{2} \mathrm{O}_{2}$ ) react spontaneously (16), these two products of eNOS would be expected to suppress each other's effects although the product of their interaction, peroxynitrite, is itself vasoactive. The physiological effects of NO and superoxide anions may depend crucially on their local concentrations and their intracellular site of formation. In order to accumulate as $\mathrm{H}_{2} \mathrm{O}_{2}$, endothelial superoxide anions must first escape interacting with $\mathrm{NO}$ molecules; under normal conditions, at least in some blood vessels, it appears that a small amount of superoxide anions survives for long enough to be acted on by SOD and generate $\mathrm{H}_{2} \mathrm{O}_{2}$. However, in other healthy vessels, such as the large cerebral arteries (4, 18 ), and under pathological situations in many blood vessels, the production of superoxide anions (largely from sources other than eNOS) may overwhelm the production of NO. Under these conditions, $\mathrm{H}_{2} \mathrm{O}_{2}$ production will be limited only by the availability of SOD, and endotheliumderived peroxynitrite, prostanoids, and possibly isoprostanes may tip the balance toward vasoconstriction (Figure 2). In addition, massive scavenging of NO will unleash the production and permit the action of endothelin-1, accelerating the evolution toward pathology (20).

\footnotetext{
Figure 2

Proposed interactions between $\mathrm{NO}$ and superoxide anions $\left(\mathrm{O}_{2}{ }^{-}\right)$in the regulation of endothelium-dependent responses. NO synthase (NOS) produces both NO and superoxide anions. Under normal circumstances, and in most arteries, the production of NO predominates, and $\mathrm{NO}$ scavenges the small amounts of superoxide anion formed. In the small mesenteric artery of the mice, the superoxide anions that escape the scavenging by $\mathrm{NO}$ are transformed by SOD to $\mathrm{H}_{2} \mathrm{O}_{2}$, which diffuses to the vascular smooth muscle and causes its hyperpolarization (Hyperpol.) by opening of a $\mathrm{K}^{+}$conductance $\left(\mathrm{K}_{\mathrm{Ca} 2^{+}}\right)$. $\mathrm{NO}$ activates soluble guanylate cyclase (sGC) to produce more cGMP. In arteries such as the canine cerebral arteries, or the aortas of hypertensive or diabetic animals, other sources of production of superoxide anions (e.g., $\mathrm{NAD}(\mathrm{P}) \mathrm{H}$ oxidase $[\mathrm{NAD}(\mathrm{P}) \mathrm{H} \mathrm{Ox}]$ ) or xanthine oxidase (Xant $\mathrm{Ox}$ ) are activated when the intracellular $\mathrm{Ca}^{2+}$ concentration increases. The large quantities of superoxide anions formed scavenge most or all of the NO, leading to the production of peroxynitrite $\left(\mathrm{ONOO}^{-}\right)$. In addition, superoxide anions can be transformed to hydroxyl radicals, which diffuse to the vascular smooth muscle and induce the production of vasoconstrictor endoperoxides $\left(\mathrm{PGH}_{2}\right)$ and prostanoids (and possibly isoprostanes). The latter activate TP receptors (TP-R) that are coupled positively to the contractile process.
}

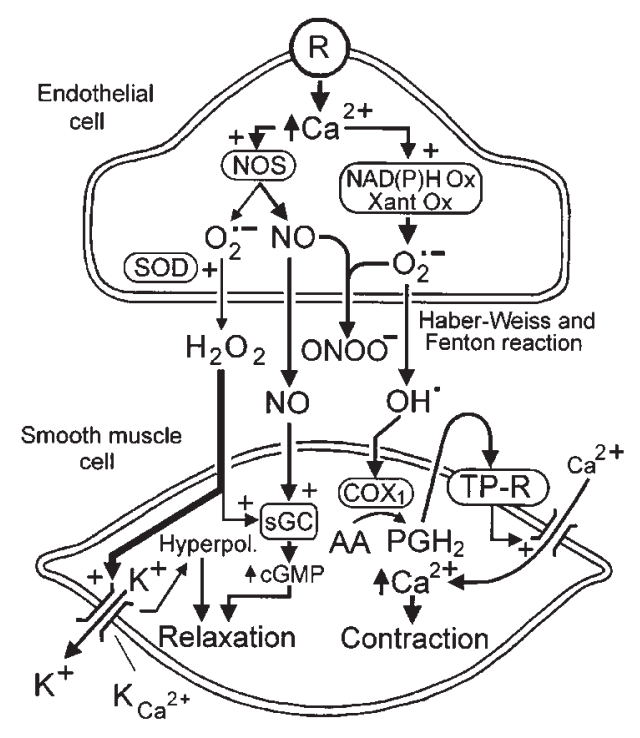




\section{Explaining physiological differences among blood vessels}

The multiplicity of pathways defined so far to explain endothelium-dependent hyperpolarization (Figure 1) implies a delicate equilibrium between several signaling molecules produced by the endothelial cells. The importance of the various mediators that influence this vascular response may vary across blood vessels of different species, anatomical origin, or size, and may depend on their differential synthesis or secretion by endothelial cells. Such an explanation focuses on putative heterogeneity among endothelial cells in these different settings, but it is equally plausible that endothelial cells are generally similar in their secretion of vasoactive factors in response to increased intracellular $\mathrm{Ca}^{2+}$ concentration (Figure 1) and that the explanation for heterogeneous vascular physiology lies elsewhere. $\mathrm{H}_{2} \mathrm{O}_{2}$ and the other vasoactive factors may take on greater or lesser importance in different settings depending on their diffusion properties, their stability in the local environment, and the sensitivity of the vascular smooth muscle to their effects. Differences in responsiveness of vascular smooth muscle to these mediators may be determined by its genetic background and its chronic local environment. A strong hint indicating the importance of vascular smooth muscle comes from the long- standing observation that exogenous $\mathrm{NO}$, given to cardiac patients in the form of nitrates, relaxes large coronary arteries, but not small coronary arteries in which EDHF-mediated responses are prominent. For the patient, this differential response offers the advantage that nitrates, unlike some other dilators, do not divert blood flow from the healthy myocardium. For the endothelial biologist, fascinated by the quest for the identity of EDHF, it prompts the humbling thought that it is the smooth muscle, not the endothelial cell, that determines which endothelium-derived factors are important in a given blood vessel.

1. Matoba, T., et al. 2000. Hydrogen peroxide is an endothelium-derived hyperpolarizing factor in mice. J. Clin. Invest. 106:1521-1530.

2. Furchgott, R.F., and Vanhoutte, P.M. 1989 Endothelium-derived relaxing and contracting factors. FASEB J. 3:2007-2017.

3. Moncada, S., and Higgs, A. 1993. The L-argininenitric oxide pathway. N. Engl. J. Med. 329:2002-2012.

4. Katusic, Z.S., and Vanhoutte, P.M. 1989. Superoxide anion is an endothelium-derived contracting factor. Am. J. Physiol. 257:H33-H37.

5. Edwards, G., Dora, K.A., Gardener, M.J., and Garland, C.J. 1998. $\mathrm{K}^{+}$is an endothelium-derived hyperpolarizing factor in rat arteries. Nature. 396:269-272.

6. Vanhoutte, P.M., editor. 1998. Endothelium-derived byperpolarizing factor. Harwood Academic Publishers. Amsterdam, The Netherlands. 335 pp.

7. Vanhoutte, P.M., editor. 1999. Endothelium-dependent hyperpolarizations. Harwood Academic Publishers. Amsterdam, The Netherlands. 433 pp.

8. Vanhoutte, P.M., editor. EDHF 2000. Harwood Academic Publishers. Amsterdam, The Netherlands. In press.
9. Beny, J.L., and von der Weid, P.Y. 1991. Hydrogen peroxide: an endogenous smooth muscle cell hyperpolarizing factor. Biochem. Biophys. Res. Commun. 176:378-384.

10. Hayabuchi, Y., Nakaya, Y., Matsuoka, S., and Kuroda, Y. 1998. Hydrogen peroxide-induced vascular relaxation in porcine coronary arteries is mediated by $\mathrm{Ca}^{2+}$-activated $\mathrm{K}^{+}$channels. Heart Vessels. 13:9-17.

11. Barlow, R.S., and White, R.E. 1998. Hydrogen peroxide relaxes porcine coronary arteries by stimulating $\mathrm{BK}_{\mathrm{Ca}}$ channel activity. Am. J. Physiol. 275:H1283-H1289.

12. Rubanyi, G.M., and Vanhoutte, P.M. 1986. Oxygen-derived free radicals, endothelium and responsiveness of vascular smooth muscle. Am. J. Physiol. 250:H815-H821.

13. Stroes, E., et al. 1998. Origin of superoxide production by endothelial nitric oxide synthase. FEBS Lett. 438:161-164.

14. Vasquez-Vivar, J., et al. 1998. Superoxide generation by endothelial nitric oxide synthase: the influence of cofactors. Proc. Natl. Acad. Sci. USA. 95:9220-9225.

15. Kaesemeyer, W.H., Ogonowski, A.A., Jin, L., Caldwell, R.B., and Caldwell, R.W. 2000. Endothelial nitric oxide synthase is a site of superoxide synthesis in endothelial cells treated with glyceryl trinitrate. Br. J. Pharmacol. 131:1019-1023.

16. Rubanyi, G.M., and Vanhoutte, P.M. 1986. Superoxide anions and hyperoxia inactivate endothelium-derived relaxing factor(s). Am. J. Physiol. 250:H822-H827.

17. Auch-Schwelk, W., Katusic, Z.S., and Vanhoutte, P.M. 1989. Contractions to oxygen-derived free radicals are augmented in aorta of the spontaneously hypertensive rat. Hypertension. 13:859-864.

18. Katusic, Z., Shepherd, J.T., and Vanhoutte, P.M. 1987. Endothelium-dependent contraction to stretch in canine basilar arteries. Am. J. Physiol. 21:H671-H673.

19. Olmos, L., Mombouli, J.V., Illiano, S., and Vanhoutte, P.M. 1995. cGMP mediates the desensitization to bradykinin in isolated canine coronary arteries. Am. J. Physiol. 268:H865-H870.

20. Vanhoutte, P.M. 2000. Say NO to ET. J. Auton. Nerv. Syst. 81:271-277. 